
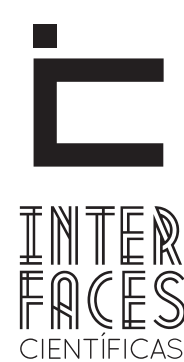

SAÚDE E AMBIENTE

\title{
ASPECTOS ÉTICOS E LEGAIS DA ORDEM DE NÃO RESSUSCITAR - PERCEPÇÃO DO ENFERMEIRO
}

Emília Cervino Nogueira ${ }^{1}$

Thuany Gois Monteiro ${ }^{3}$
Tácia Viviany Santana Santos ${ }^{2}$

\section{RESUMO}

No Brasil a Ordem de Não Ressuscitar ainda não possui amparo legal, visto que a padronização das condutas no processo a ser realizado depende do raciocínio moral e da sensibilidade ética envolvendo a identificação dos aspectos éticos de cada situação. 0 objetivo deste trabalho é identificar a percepção do enfermeiro que atua no setor de oncologia de um hospital de Aracaju sobre os aspectos éticos e legais diante da Ordem de Não ressuscitar. É um estudo investigativo com abordagem quantitativa realizado em um hospital de Aracaju - SE, com os enfermeiros do setor de oncologia, tendo como instrumento de coleta de dados um questionário contendo 15 perguntas objetivas. Os dados obtidos foram analisados com o auxílio do programa Epi Info versão 7. Os resultados estão sendo apresentados na forma de análise descritiva. Dos 13 enfermeiros que atuam na ala de oncologia do hospital, 10
(76,9\%) concordaram em participar da pesquisa. Destes, $60 \%$ afirmam que a conduta a ser tomada diante uma parada cardiorrespiratória é utilizar todos os recursos possíveis para a reanimação, entretanto, levando em consideração o quadro clínico do paciente, sendo este terminal, executariam a Ordem de Não Ressuscitar. Nesta pesquisa observou-se que a maioria dos enfermeiros realiza a Ordem de Não Ressuscitar, relatando que esta é prescrita em prontuário e acreditando ser uma decisão médica. Porém não existem protocolos frente a esta tomada de decisão, deixando os profissionais desamparados pela legislação.

\section{PALAVRAS CHAVE}

Reanimação Cardiopulmonar. Doente terminal. Enfermagem. Ética 


\section{ABSTRACT}

In Brazil, the Do Not Resuscitate Order does not have legal support, since the standardization of approaches in the process to be performed depends on the moral reasoning and ethical sensitivity involving the identification of the ethical aspects of each situation. The objective of this work is to identify the perception of nurses who work in the cancer ward of a hospital in Aracaju on the ethical and legal aspects on the Order of not resuscitate. It is an investigative study with quantitative approach undertaken in a hospital in Aracaju - SE, with nurses from the oncology sector, as the data collection instrument was a questionnaire containing 15 objective questions. Data were analyzed using Epi Info version 7 program. The results are presented in the form of descriptive analysis. Of the 13 nurses working in hospital oncology ward, 10

\section{RESUMEN}

En Brasil, la Orden de No Resucitar no tiene apoyo legal, ya que la estandarización de los enfoques en el proceso a realizar, depende del razonamiento moral y la sensibilidad ética, que por su vez, implica en la identificación de los aspectos éticos de cada situación. El objetivo de este trabajo es identificar la percepción de los enfermeros que trabajan en la sala de oncología de un hospital en Aracaju, sobre los aspectos éticos y legales frente a la Orden de no Resucitar. Se trata de un estudio de investigación con enfoque cuantitativo, llevado a cabo en un hospital de Aracaju - SE, con enfermeros del sector de oncología, teniendo como instrumento de recolección de datos un cuestionario con 15 preguntas objetivas. Los datos se analizaron usando Epi Info de la versión 7. Los resultados se presentan en la forma de análisis descriptivo. De los 13 enfermeros que trabajan en
(76.9\%) agreed to participate. Of these, $60 \%$ say that the action to be taken before the cardiac arrest is to use all possible resources for resuscitation, however, taking into account the clinical picture of the patient, and this terminal would perform the Order of Do Not Resuscitate. In this study it was observed that most nurses performs the Order of Do Not Resuscitate, reporting that this is prescribed in medical charts and believing it to be a medical decision. But there are no protocols against this decision-making professionals helpless by law.

\section{KEYWORDS}

Cardiopulmonary Resuscitation. Terminal Patient. Nursing. Ethics. sala de oncología del hospital, 10 (76,9\%) aceptaron participar. De éstos, el $60 \%$ dice que la acción a ser tomada antes del paro cardíaco es utilizar todos los recursos posibles para la reanimación, teniendo en cuenta el cuadro clínico del paciente, se éste es terminal sería realizar la orden de no resucitar. En este estudio se observó que la mayoría de las enfermeras realiza la Orden de No Resucitar, informando de que así lo prescriban las historias clínicas y creyendo que es una decisión médica. Pero, no existen protocolos legales, dejando así a éstos profesionales desamparados por la ley.

\section{PALABRAS CLAVE}

Reanimación Cardiopulmonar. Enfermo Terminal. Enfermería. Ética 


\section{INTRODUÇÃO}

A parada cardiorrespiratória (PCR) tem como definição a interrupção das atividades respiratória e circulatória efetivas, constituindo-se um evento dramático. As discussões éticas nos assuntos relacionados ao fim da vida partem tanto de iniciar, quanto interromper a ressuscitação cardiopulmonar. No Brasil, as ordens de não ressuscitação, ainda, não possuem amparo legal, nem há previsão de documentá-la, razão pela qual não existe padronização das condutas no processo dessa tomada de decisão, que depende de raciocínio moral e sensibilidade ética e envolve a identificação dos aspectos éticos de cada situação, visto que pode afetar o bem-estar do indivíduo no que diz respeito aos seus desejos ou necessidades para uma resposta ou ação apropriada (LUZIA; LUCENA, 2009; TRIGUEIRO ET AL., 2010).

A reanimação cardiopulmonar (RCP) é decisória para os outros procedimentos de suporte avançado de vida, que serão mantidos ou iniciados apenas em caso de ressuscitação bem sucedida. A RCP é iniciada sem prescrição, e para interrompê-la é necessária ordem médica, levando em consideração diversos fatores. Diante de uma parada cardíaca a intervenção médica deve ser avaliada de acordo com o quadro clínico do paciente, sabendo a origem desta, se é patológica ou desfecho biológico de um ciclo de nascimento, vida e morte, comum a todos os seres vivos (TORRES; BATISTA, 2008).

Os cuidados paliativos têm como ideologia acolher a pessoa, na fase final da vida, na sua globalidade de ser, promovendo o bem estar e a dignidade do paciente crônico e terminal. Tais cuidados ao paciente possibilitam de não ser expropriado do momento final de sua vida, mas de viver a própria morte, estando preparado para dar continuidade a um tratamento que não resulta em cura, mas sim aceitando a sua morte (CHAVES ET AL., 2011).

Com a evolução humana, a percepção da morte foi se transformando e tomando uma proporção dife- renciada na vida das pessoas. A tecnologia em saúde e a dependência da equipe profissional em relação à mesma aumentaram o controle sobre o tempo de vida e as circunstâncias da morte, diminuindo o contato direto com o paciente terminal. As medidas terapêuticas sem perspectiva de cura, não são indicadas, pois prolongam a vida sem chance de recuperação (SANTANA ET AL., 2009).

A cura da doença e o alívio do sofrimento é um dos objetivos da medicina. A doença destrói a integridade do corpo, enquanto a dor e o sofrimento podem destruir a integridade global da pessoa. 0 sofrimento é uma questão pessoal e a dor está voltada para o lado físico do enfermo, podendo causar o sofrimento. Embora a dor física seja a fonte mais comum de sofrimento, a dor enfrentada pelo paciente terminal vai além do físico, tendo conotações culturais, subjetivas, sociais, psíquicas e éticas (PESSINI, 2009).

É de grande importância a união dos cuidados paliativos a uma proposta de cuidados mais humanizada, não como uma obrigação, mais sim como um ato de respeito e solidariedade com o paciente e seus familiares, proporcionando assim o alívio do sofrimento ocasionado pela doença (SANTANA ET AL., 2009).

Um dos problemas encontrados na Ordem de Não Ressuscitar (ONR) é que os enfermeiros não têm ação direta na tomada de decisão; isso não os impede de questionar as ações propostas quando há discordância, numa tentativa de levar o médico a uma reflexão sobre sua conduta. Este tipo de atitude é uma das múltiplas formas que encontram para demonstrar seu conhecimento técnico-científico e sua autonomia perante a equipe, demonstrando que o papel do enfermeiro na equipe de saúde é indispensável (TRIGUEIRO ET AL., 2010).

Para Pessini (2009), o principal objetivo da medicina é a preservação da vida e a restauração da saúde, a morte deve ser entendida e esperada como ultima alternativa, reconhecendo que o aumento e desen- 
volvimento tecnológico abriram portas para inúmeras formas de tratamento. A medicina deve estar sempre disposta e esforçada para lutar em favor da vida. Sendo assim, entende-se que a morte é parte do ciclo da vida humana, portanto cuidar do corpo que está morrendo deve ser parte integral dos objetivos da medicina.

A inexistência de protocolos frente ao paciente terminal, fora de condições terapêuticas dentro do âmbito hospitalar ocasiona dilemas éticos e conflitos na equipe de saúde, dificultando a tomada de decisão diante da proximidade da morte em pacientes terminais, questão que, embora já explorada e analisada, ainda deixa lacunas, principalmente no aspecto da ética, razão pela qual desenvolvemos este estudo.

Diante do exposto, o presente estudo visou identificar a percepção do enfermeiro que atua no setor de oncologia de um hospital de Aracaju sobre os aspectos éticos e legais diante da Ordem de Não Ressuscitar.

\section{METODOLOGIA}

Trata-se de um estudo investigativo com abordagem quantitativa que foi realizado em um hospital de Aracaju SE, no segundo semestre de 2013, visando identificar a percepção do enfermeiro que atua no setor de oncologia sobre os aspectos éticos e legais diante da Ordem de Não Ressuscitar.

Foram inclusos na pesquisa os enfermeiros da ala de oncologia de todos os turnos de trabalho da instituição, que concordaram em participar após o esclarecimento sobre o estudo e a assinatura do Termo de Consentimento Livre e Esclarecido (TCLE). Foram exclusos os profissionais que estavam de folga, férias ou licença durante o período da coleta, ou que não concordaram em participar da pesquisa.

O projeto foi aprovado pelo Comitê de Ética em Pesquisa (CEP) da Universidade Tiradentes (UNIT) sob o número CAAE 20265113.1.0000.5371.
Para coleta de dados e informações, foi aplicado um questionário, contendo perguntas fechadas, perfazendo o total de quinze itens. As questões trataram especificamente sobre a ONR, considerando os aspectos éticos e legais que envolvem essa questão. 0 questionário foi elaborado pelas próprias pesquisadoras e validado por dois juízes com ampla experiência na área.

Os dados obtidos foram inseridos numa planilha Microsoft EXCEL versão 2010 e analisados com o auxílio do programa Epi Info versão 7. Os resultados estão sendo apresentados na forma de análise descritiva.

\section{RESULTADOS E DISCUSSÃO}

Dos 13 enfermeiros que atuam na ala de oncologia do hospital, $10(76,9 \%)$ concordaram em participar da pesquisa, dois $(15,4 \%)$ se recusaram, referindo falta de tempo para responder o instrumento e um $(7,7 \%)$ estava de férias.

Para $60 \%$ dos enfermeiros pesquisados, a conduta a ser tomada diante uma parada cardiorrespiratória (PCR) é utilizar todos os recursos possíveis, realizando as manobras de reanimação cardiorrespiratória (RCP) e administração de drogas vasoativas, 30\% deles afirmaram exercer a ONR o paciente e $10 \%$ responderam que utilizam todos os recursos e exercem a ONR; nenhum deles admitiu aguardar o médico para tomada de decisão.

A tomada de decisão exige uma análise minuciosa do contexto sociocultural, e tem como base habilidades técnicas e éticas, conhecimento teórico, profissionalismo, autonomia, valores pessoais, confiança e propensão a assumir riscos. 0 agir do enfermeiro não requer somente a prática em realizar o cuidado assistencial e conhecimento teórico, mas também uma formação moral e ética que o norteie e sustente em uma tomada de decisão, pois trabalha cotidianamente com vidas (TRIGUEIRO ET AL., 2010). 
Levando em consideração o quadro clínico do paciente, sendo este terminal, $40 \%$ dos enfermeiros executariam as manobras de reanimação e $60 \%$ não executariam. Uma pesquisa realizada em um Hospital do interior de Minas Gerais, que teve como objetivo compreender o significado atribuído pela equipe de enfermagem aos cuidados paliativos com pacientes terminais a partir de relatos verbais da equipe de enfermagem, concluiu que realizar a RCP é prolongar o sofrimento tanto do paciente quanto da família (SANTANA ET AL., 2009). Podem-se observar resultados semelhantes no presente estudo, com a maioria dos entrevistados a favor da Não Reanimação.

Chama-se atenção ao fato de que o mesmo quantitativo (60\%) de enfermeiros que afirmam utilizar todos os recursos possíveis diante de uma PCR relatam que não executariam as manobras de reanimação cardiorrespiratória, em caso de paciente terminal, levando-se em consideração o seu quadro clínico.

Segundo Trigueiro e outros autores (2010), o direito à vida não envolve um dever de vida artificial a qualquer custo. Suspender o tratamento não é encurtar o tempo de vida, é deixar de prolongar em dias ou horas uma existência sem benefício para o indivíduo. Neste sentido, o princípio bioético da justiça deve ser respeitado quando ocorre a ONR, em caso de paciente terminal. A RCP sem perspectiva de cura não é indicada, podendo ser fútil ou cruel, pois prolonga a vida sem chances de recuperação.

De acordo com Clemente e Santos (2007), é de responsabilidade médica avaliar o quadro do paciente, no que se refere ao possível estado de irreversibilidade e o prognóstico da doença para contraindicar manobras de ressuscitação e, assim, evitar ressuscitar um paciente para morrer um pouco mais tarde por meio da instituição de uma terapia agressiva, a qual só irá prolongar o processo agônico, aumentar o desconforto e a dependência, e diminuir a qualidade de vida do paciente e sua família.
Ao serem questionados sobre de quem é a opção por não reanimar o paciente em caso de PCR, 70\% responderam ser dos médicos e $30 \%$ dos médicos e familiares destes pacientes. Nenhum deles respondeu que a opção seria do enfermeiro ou do paciente.

Em um estudo realizado em dois hospitais portugueses com especialidade em oncologia, no que se refere à questão de quem toma e quem ajuda na decisão da ONR, os resultados obtidos indicam que os enfermeiros consideraram que a decisão era tomada em $43,3 \%$ das vezes sempre pelo médico assistente, com a participação e ajuda da equipe médica (64,1\%), do doente quando competente $(49,4 \%)$ e da equipe de enfermagem (40,3\%) (FRANÇA ET AL., 2010). Com isso, é possível concluir que a decisão por não reanimar o paciente é, na maioria das vezes, tomada pelo médico.

Figueiredo e outros autores (2010) afirmam que o indivíduo portador de câncer sofre sérias modificações em função do processo da doença, desencadeando uma crise vital no indivíduo e em sua família. Diante desse quadro, é preciso desenvolver uma forma de trabalhar o psicológico do paciente juntamente com a sua família para que estes estejam preparados para o fim do tratamento paliativo, onde os temores da dor e da morte são a única certeza, e é neste quadro que os profissionais de enfermagem utilizam suas habilidades.

Levando em consideração a afinidade com o paciente e seu quadro clínico, tendo como base a sua experiência acadêmica e profissional, $60 \%$ dos enfermeiros acreditam que os médicos estão mais aptos a decidir sobre ONR, $30 \%$ os enfermeiros e $10 \%$ acreditam que os médicos e familiares é quem devem decidir sobre a ONR.

As ONR têm importantes implicações éticas. 0 respeito à dignidade da pessoa humana é o valor mais importante e com base nele é que todas as decisões devem ser tomadas. Os fatores que influenciam a tomada de decisão em momentos complicados para a resolução de dilemas éticos relacionados à reanima- 
ção são: o esclarecimento da família e do paciente, a postura coerente dos profissionais de saúde envolvidos e ainda a observação dos princípios bioéticos (SORATTO; SILVESTRINI, 2010).

Em relação à situação em que é exercida a ordem de não ressuscitar, $40 \%$ dos enfermeiros consideram o paciente terminal, $40 \%$ afirmam ser a melhor conduta, $10 \%$ a vontade do paciente e de seus familiares e $10 \%$ acreditam ser a melhor conduta e também a vontade do paciente. Para $70 \%$ dos enfermeiros, os fatores que norteiam a decisão da suspensão da RCP são o quadro clínico do paciente, $10 \%$ deles declaram que é decisão do paciente em não querer dar continuidade ao tratamento e $20 \%$ todas as alternativas, sendo estas o quadro clínico do paciente, a decisão do paciente em não querer dar continuidade ao tratamento, a ordem médica e o desejo dos familiares.

Diante dos resultados, pudemos observar que nas questões anteriores, a vontade do paciente não foi levada em consideração, e nesta se fez presente em $10 \%$ dos casos contradizendo as questões anteriores.

No Brasil, não é comum aparecer formalmente registrada em prontuário a ordem de não ressuscitação. Tal conduta é adotada na prática hospitalar por modos verbais, informais e unilaterais, infringindo o princípio da autonomia (SILVA ET AL., 2007). Na Unidade pesquisada, $60 \%$ dos enfermeiros afirmaram que a ONR é registrada em prontuário e $40 \%$ referiram que é dada verbalmente.

Em uma pesquisa realizada em Hospitais de Portugal, segundo a maioria dos enfermeiros (85,3\%), a ONR é escrita no prontuário enquanto $14,3 \%$ indicaram que era apenas comunicado oralmente, o que não está em conformidade com os padrões de atuação internacionalmente aceitos. Em ambas as pesquisas foram observadas a prevalência da ordem prescrita em prontuário.

A não indicação em prontuário da ONR abre uma lacuna na abordagem do doente por outros profissionais de saúde, quer numa urgência, quer na presença de alguém que desconheça essa decisão. Tal atitude não é considerada adequada, pois levanta muitas dúvidas e pode conduzir à prática da obstinação terapêutica pela falha na transmissão de informação e por esta não se encontrar registrada (FRANÇA ET AL., 2010).

Nos casos em que o paciente não deixou diretivas prévias e não tendo nenhum responsável por este, a conduta de realizar ou não a ONR é de responsabilidade médica. A atuação médica se baseia classicamente em dois princípios; o primeiro é a preservação da vida que significa manter o paciente vivo em condições razoáveis, respeitando os princípios éticos e legais como também a vontade deste; e o segundo é o alívio do sofrimento que é dado através de medidas terapêuticas (MOHALLEM; RODRIGUES, 2007). Correlacionando a ordem de não reanimar com as possíveis implicações legais da questão $90 \%$ não consideram um caso de omissão de socorro e $10 \%$ consideram que sim.

Entre 1984 e 1993, enfermeiros de terapia intensiva de vários hospitais participaram de um levantamento para identificar questões éticas enfrentadas pela maioria deles, sendo que a decisão sobre Não Ressuscitar ficou em primeiro lugar, demonstrando o quanto tal questão tem preocupado esses profissionais (SCHELL; PUNTILLO, 2005). Mesmo diante desta questão foi possível observar, na pesquisa atual, que nenhum dos profissionais está ou esteve envolvido em algum processo judicial.

A inexistência de protocolos frente ao paciente terminal, fora de condições terapêuticas, dentro do âmbito hospitalar, ocasiona dilemas éticos e conflitos na equipe de saúde, dificultando a tomada de decisão diante da proximidade da morte em pacientes terminais. No Brasil, as ordens de não ressuscitação, ainda, não possuem amparo legal, nem há previsão de documentá-la, razão pela qual não existe padronização das condutas no processo desta tomada de decisão (LUZIA; LUCENA, 2009; TRIGUEIRO ET AL., 2010). $\mathrm{Na}$ instituição, segundo $90 \%$ dos entrevistados, não 
existe protocolos para orientar a tomada de decisão. 0 mesmo resultado foi encontrado ao se questionar a existência de amparo da legislação frente à ONR.

De acordo com o Código de Ética dos Profissionais de Enfermagem (COFEN, 2007) a enfermagem é uma profissão comprometida com a saúde e a qualidade de vida da pessoa, família e coletividade. 0 profissional de enfermagem atua na promoção, prevenção, recuperação e reabilitação da saúde, com autonomia e em consonância com os preceitos éticos e legais. 0 artigo 18 do capitulo I determina ser dever e responsabilidade do enfermeiro respeitar, reconhecer e realizar ações que garantam o direito da pessoa ou de seu representante legal de tomar decisões sobre sua saúde, tratamento, conforto e bem estar. Foi possível observar que, apesar do Código de Ética, retratar sobre o respeito à vida e a dignidade da pessoa humana, ao mesmo tempo ele é omisso em relação aos cuidados paliativos, deixando o profissional de Enfermagem inseguro e desamparado frente a uma ONR.

Pode-se observar, por meio dos dados, que na Unidade a prática da ONR é frequente para $90 \%$ dos enfermeiros. Ao se questionar o motivo para se executar a ONR, todos responderam que é promover o alivio do sofrimento.

Ao se comparar as respostas anteriores, percebe-se que embora $40 \%$ dos enfermeiros afirmem que executam as manobras de reanimação mesmo em pacientes terminais, $90 \%$ confirmam a prática da ONR na Unidade.

A Organização Mundial da Saúde (OMS), em 2002, conceituou os cuidados paliativos como: medidas que aumentam a qualidade de vida de pacientes e seus familiares que enfrentam uma doença terminal, por meio de prevenção e alívio, destacando-se a importância das práticas de enfermagem desenvolvidas com o enfermo, promovendo o conforto e o bem-estar do paciente, mesmo em momentos difíceis (FIGUEIREDO ET AL., 2010). Sendo assim os pesquisadores questionaram aos enfermeiros "caso o paciente que estivesse em cuidados paliativos fosse um ente querido, você, como profissional, executaria a Ordem de Não Reanimar?” 70 \% destes responderam que sim e $30 \%$ que não executariam a ONR.

Os profissionais de saúde enfrentam dificuldades para lidar com a morte, percebe-se que a grande maioria não encontra um suporte adequado no ambiente de trabalho. Sendo assim, é necessário aprender a lidar com as perdas em um contexto de doença sem prognóstico. Este é um desafio que poucos se disponibilizam a discutir, e muito menos a enfrentar (SANTANA ET AL., 2009).

\section{CONCLUSÃO}

Cuidar de pacientes em cuidados paliativos exige além de conhecimento técnico-científico, é preciso compreender a sua individualidade, a partir de um convívio interpessoal de valorização da pessoa humana, atuando com o processo de humanização dos cuidados. Nesta pesquisa observou-se que a maioria dos enfermeiros realiza a Ordem de Não Ressuscitar, relatando que a ONR é prescrita em prontuário e acreditando ser uma decisão médica. Porém não existem protocolos frente a esta tomada de decisão, deixando os profissionais desamparados pela legislação. Entretanto, pode-se concluir que os enfermeiros do setor de oncologia estão aptos a lidar com o tema polêmico abordado na pesquisa, por esta ser a realidade enfrentada diariamente pelos enfermeiros do setor. 


\section{REFERÊNCIAS}

CHAVES, J.H.B. et al. Cuidados paliativos na prática médica: contexto bioético. Revista Dor, v.12, n.3, São Paulo, 2011. p.250-255.

CLEMENTE, R.P.D.S.; SANTOS E.H. A não-ressuscitação, do ponto de vista da enfermagem, em uma unidade de cuidados paliativos Oncológicos. Revista Brasileira de Cancerologia. v.53, n.2, 2007. p.231-236.

COFEN. Conselho Federal de Enfermagem. Resolução $n^{\circ} 311$ de 8 de fevereiro de 2007. Código de ética dos profissionais de enfermagem. Disponível em: <http://www.ipebj.com.br/docdown/_3aca5.pdf >. Acesso em: 23 out. 2013.

FIGUEIREDO, et al. Enfermagem Oncológica: conceitos e práticas. São Caetano do Sul, SP:Yendis, 2010.

FRANÇA, D. et al. Ordem de não reanimar o doente terminal: dilemas éticos dos enfermeiros. Revista Bioética, v.18, n.2, 2010. p.469- 481.

LUZIA, M. F.; LUCENA, A. F. Parada cardiorrespiratória do paciente adulto no âmbito intra-hospitalar: subsídios para a enfermagem. Revista Gaúcha Enfermagem, v.30, n.2, jun 2009. p.328-337.
MOHALLEM; RODRIGUES. Enfermagem Oncológica. Barueri, SP: Manole, 2007.

PESSINI, L. Distanásia: Até quando agir sem agredir? Revista Bioética, v.4, n.1, 2009.

SANTANA, J.C.B. et al. Cuidados Paliativos aos pacientes terminais: percepção da equipe de Enfermagem. Centro Universitário São Camilo, v.3, n.1, 2009. p.7786.

SCHELL; PUNTILLO. Segredos em enfermagem na terapia intensiva. Porto Alegre: Artmed, 2005.

SILVA, C. H. D. et al. Não-ressuscitação em medicina paliativa. Revista brasileira de Cancerologia, v. 53 n.2, 2007. p.223-224.

SORATTO, M.T.; SILVESTRINI, F. Dilemas éticos da equipe de enfermagem frente à ordem de não ressuscitar. Revista BIOETHIKOS - Centro Universitário São Camilo, v.4, n.4, 2010. p.431-436.

TORRES, R. V. S. D.; BATISTA, K. T. A ordem de não ressuscitar no Brasil, considerações éticas. Com. Ciências Saúde, v.19, n.4, 2008. p.343-351.

TRIGUEIRO, T. H. et al. Dilemas éticos vividos pelos enfermeiros diante da ordem de não reanimação. Cienc Cuid Saude. v.9, n.4, out/dez. 2010. p.721-727. 
1. Enfermeira. Mestre em Ciências da Saúde. Professora do Curso de Enfermagem da Universidade Tiradentes - UNIT. E-mail: jienogueira@ ig.com.br

Recebido em: 6 de Maio de 2014

Avaliado em: 8 de Agosto de 2014

Aceito em: 15 de Novembro de 2014
2. Enfermeira pela Universidade Tiradentes - UNIT.

3. Enfermeira pela Universidade Tiradentes - UNIT. 
